\title{
A new way of collecting and filling data in the outpatient clinic for proctologic diseases L Moletta* and P Petrin
}

\author{
Address: Clinica Chirurgica IV, Padova, Italy
}

* Corresponding author

\author{
from XXI Annual Meeting of The Italian Society of Geriatric Surgery \\ Terni, Italy. 4-6 December 2008 \\ Published: I April 2009 \\ BMC Geriatrics 2009, 9(Suppl I):A38 doi:I0.II86/I47I-23 I8-9-SI-A38
}

This abstract is available from: http://www.biomedcentral.com/I47I-23 I8/9/SI/A38

(c) 2009 Moletta and Petrin; licensee BioMed Central Ltd.

\begin{abstract}
Aim of the study
Proctologic diseases appear to be more frequent in geriatric age: constipation, hemorrhoids and rectal prolapse are some of the most frequent ano-rectal disorders in elderly patients. Repeated clinical controls of the patients are necessary for monitoring the evolutions of the clinical conditions. The usual written report can hardly outline the objective situation and define the changes obtained by the performed treatments. A new method of recording the proctologic outpatients' data, by means of a specific electronic file, has been tested. The aim is to reach a precise visual documentation of the pathologic situation before and after the treatments required as well as to electronically record, easily recall and statistically process the patients' data.
\end{abstract}

\section{Materials and methods}

The electronic database has been created utilizing Microsoft Office Access 2007. In each patient file are stored the digital images obtained by means of a reflex Canon EOS 400D camera with macro lens and flash. In the presence of intraluminal pathologic condition, a craftmade proper introducer has been attached to the camera so adapting the lens to the caliber of the anoscope.

\section{Results}

The new method of filing has been applied on 112 outpatients visited between January and October 2008, and retrospectively on 318 outpatients visited between January 2004 and December 2007. The mean age was 52.05 years (range: 23-95 years, standard deviation: 16.34): 20\% of patients was older than 65 . Among these patients, the most frequently complained symptoms were small amounts of red bleeding (with a frequency of $60 \%$ at the first visit), anal pain (35\%), bowel disorders (28\%). The three most frequent diagnosis were hemorrhoids $(60 \%$ of outpatients), fissures (13\%) and rectal prolapse (9\%). The following figures refer to rubber band ligation of mucosal prolapse, to hemorrhoids sclerotherapy and to stapled hemorrhoidopexy of grade III hemorrhoids according with Longo technique.

\section{Conclusion}

The new method of achieving and storing data and images seems able to produce some clear results in the proctologic field: quick and easy record of the clinical data, immediate and automatically updating of the statistical analysis, objective iconographic evaluation of the performed treatments efficacy. 